\title{
Development and in vitro evaluation of positive-charged solid lipid nanoparticles as nucleic acid delivery system in glioblastoma treatment
}

\author{
Gülşah Erel Akbaba 1,2, Hasan Akbaba 1, A. Gülten Kantarc1 1, * \\ 1 Department of Pharmaceutical Biotechnology, Faculty of Pharmacy, Ege University, İzmir, Turkey \\ 2 Department of Pharmaceutical Biotechnology, Faculty of Pharmacy, İzmir Katip Çelebi University, İzmir, Turkey \\ * Correspondence: gulten.kantarci@ege.edu.tr (A.G.K.); Tel: +90-232-311 25 75; fax: +90-232-388 52 58; ORCID No: 0000- \\ 0001-8813-5353.
}

Received: 21 November 2017 / Revised: 22 December 2017 / Accepted: 2 January 2018

\begin{abstract}
In this study, we aimed to develop a novel positive charged nucleic acid delivery system for the treatment of glioblastoma. For this purpose, Epidermal Growth Factor Receptor (EGFR) which plays a prominent role in glioblastoma was selected as a target. Cationic solid lipid nanoparticles (cSLN) were developed by microemulsion dilution method using cetyl palmitate as matrix lipid, Cremephor RH40 and Peceol as surfactants, and ethanol as cosurfactant. Characterization studies showed that obtained nanoparticles are positively charged and has an appropriate particle size for nucleic acid delivery $(<20 \mathrm{~nm})$. Gel retardation assay revealed that cSLNs have complexation ability with siRNA EGFR (cSLN:siRNAEGFR) and this complex is able to protect siRNA from serum- mediated degradation up to $6 \mathrm{~h}$. The cytotoxicity evaluation of nanoparticles performed on U87 Human Glioblastoma Cell Line. Furthermore, in vitro delivery of siRNA-EGFR via cSLN inhibited EGFR expression significantly at 50nM siRNA dose compared to free siRNA-EGFR at the same dose on U87 cell line $(\mathrm{p}<0.05)$. Based on these findings, we propose that the developed cSLN system may has a potential as a siRNA delivery system for glioblastoma.
\end{abstract}

KEYWORDS: Glioblastoma ; solid lipid nanoparticle ; siRNA ; gene delivery ; EGFR.

\section{INTRODUCTION}

Cancer is one of the most common causes of death in our era. According to the facts of The World Health Organization, 70\% increment in the incidence of cancer is expected for the next twenty years [1]. At the present time, there is no curative treatment for Glioblastoma, which is the highest incidence of brain tumors. Despite the therapeutic approaches, median survival for glioblastoma is only 14 months. All these facts make it necessary to develop an effective, innovative and high technology treatment options [2,3].

Genetic-based treatment approaches show promise for numerous disease from cancer to inherited illnesses. RNA interference is a specific post-transcriptional gene silencing mechanism regulated by microRNAs (miRNA), exogenous small interfering RNAs (siRNA) or small hairpin RNAs(shRNA) [4,5]. It is a current research topic which directly targets the gene that causes the diseases as a novel therapeutic approach. The main purpose of gene therapy is successfully transferring genetic material to the target cell. For this aim, viral or non-viral gene delivery systems are used. Production of non-viral delivery systems which have capacity for carrying high amounts of genetic material, low toxicity, low risk for immune responses and easy production is one of the research area of pharmaceutical sciences [6,7] .

SLNs are one of the most promising non-viral gene delivery systems due to the various advantages. Specifically, SLNs can be produced at a large scale and show long-term stability. They are usually composed of nontoxic, biodegradable lipids exhibiting low cytotoxicity $[8,9]$. SLNs could be produced in nanosize and with cationic properties which allow them to bind nucleic acids due to electrostatic interactions. The size and charge of SLNs can be modified due to various production strategies to obtain higher transfection efficiency $[10,11]$.

In this study, we developed a novel solid lipid nanoparticle by microemulsion dilution technique to obtain non-toxic, biocompatible, cationic charged SLNs with optimal size and surface properties for gene delivery. For this purpose, Epidermal Growth Factor Receptor (EGFR) which is known to be responsible for

How to cite this article: Erel Akbaba G, Akbaba H, Kantarcı AG. Development and in vitro evaluation of positive-charged solid lipid nanoparticles as nucleic acid delivery system in glioblastoma treatment. Marmara Pharm J. 2018; 22 (2): 299-306. 
excessive growth, proliferation, invasion, and metastasis on glioblastoma is selected as a target [12,13]. Obtained SLNs were characterized and then cSLN:siRNA-EGFR complexes were formed. Protection ability against serum nucleases, cytotoxicity levels, and gene silencing efficiency were examined.

\section{RESULTS AND DISCUSSION}

\subsection{Formation of pseudo-ternary phase diagram}

The pseudo-ternary phase diagram constructed over the lipid melting temperature $\left(60^{\circ} \mathrm{C}\right)$ by titration of UPH2O into the oil (cetyl palmitate), surfactants (Cremephor RH40 and Peceol) and co-surfactant (ethanol) mixture is presented in Figure 1. After construction of the phase diagram, one point in the $\mathrm{o} / \mathrm{w}$ microemulsion region was used to form SLNs as mentioned in the Methods section.

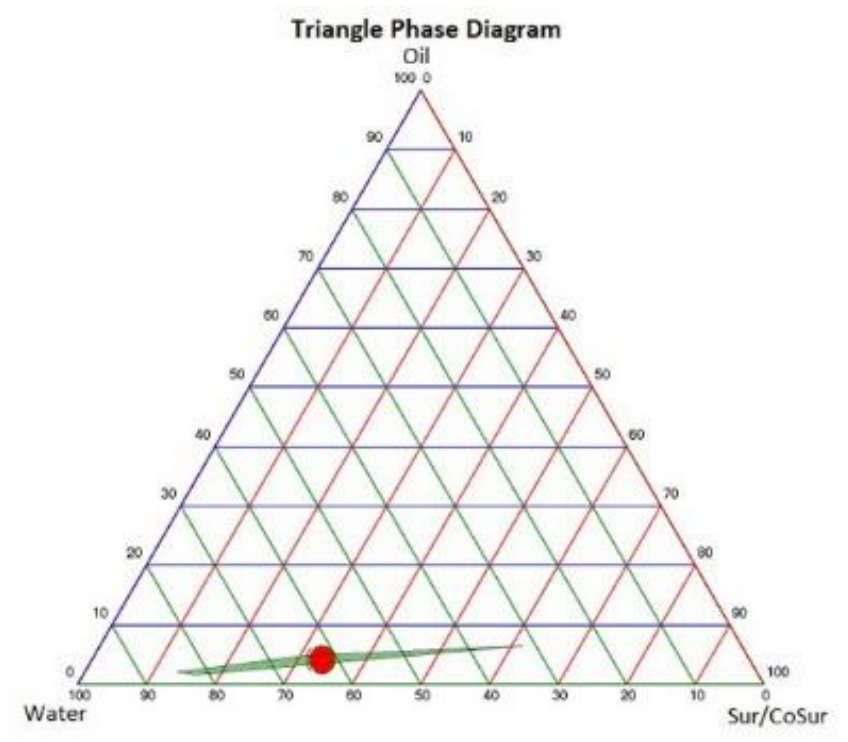

Figure 1. The pseudo-ternary phase diagram of $\mathrm{o} / \mathrm{w}$ microemulsion formed with cetyl palmitate as oil phase, Cremephor RH40:Peceol $(2: 1, \mathrm{v} / \mathrm{v})$ as surfactants, ethanol as co-surfactant and $\mathrm{UPH}_{2} \mathrm{O}$ as a dispersant. (Green area shows transparent $\mathrm{o} / \mathrm{w}$ microemulsion region, red area represents the center point of the $\mathrm{o} / \mathrm{w}$ microemulsion region).

\subsection{Size and Zeta Potential Measurements}

DLS measurements were performed in order to investigate the particle size and zeta potential of SLN, cSLN and cSLN:siRNA-EGFR (3:1, v/v) complex. As displayed in Table 1, the obtained SLNs are in the nanometer size range. SLN had a droplet size of $23.84 \mathrm{~nm}$ and when the DDAB was incorporated as a cationic charge carrier, the droplet size decreased to $18.49 \mathrm{~nm}$. Then, by the complexation of siRNA, the particle size increased to $21.48 \mathrm{~nm}$. On the other hand, by the addition of DDAB, the zeta potential of SLN increased from $4.17 \mathrm{mV}$ to $24.5 \mathrm{mV}$, as expected. Then, when the siRNA complexed with cSLN, the zeta potential decreased to $22.8 \mathrm{mV}$. This reduction in zeta potential is due to the binding of negatively charged siRNA onto the surface of positive charged nanoparticles [14,15]. Eventually, the net positive charge of the particles is sufficient to prevent particle aggregation and promote electrostatic interaction with the overall negative charge of the cell membrane for transfection [16].

Table 1. Particle size and zeta potential measurement of SLN, cSLN and cSLN: siRNA complex $(n=3)$.

\begin{tabular}{cccc}
\hline & $\begin{array}{c}\text { Particle size } \\
(\mathbf{n m})( \pm \text { SD) }\end{array}$ & PDI & Zeta Potantial (mV) $( \pm$ SD) \\
\hline SLN & $23.84 \pm 0.24$ & $0.067 \pm 0.003$ & $4.17 \pm 1.47$ \\
cSLN & $18.49 \pm 0.26$ & $0.517 \pm 0.082$ & $24.5 \pm 0.95$ \\
$\begin{array}{c}\text { cSLN:siRNA complex } \\
(\mathbf{v} / \mathbf{v})(3: 1)\end{array}$ & $21.48 \pm 0.38$ & $0.544 \pm 0.056$ & $22.8 \pm 2.42$ \\
\hline
\end{tabular}




\subsection{Gel retardation assay}

Gel retardation assay is widely used to examine the nucleic acid binding affinity of cationic nanoparticles $[17,18]$. cSLNs were evaluated for complexation ability with siRNA-EGFR using agarose gel retardation assay to determine the optimal cSLN: siRNA ratio. The migration of naked siRNA and SLN:siRNA complexes in agarose gel is shown in Figure 2. Obtained cSLNs showed RNA binding ability and the migration of siRNA in agarose gel was completely retarded when the ratio of cSLN:siRNA reached 3:1 (v/v).

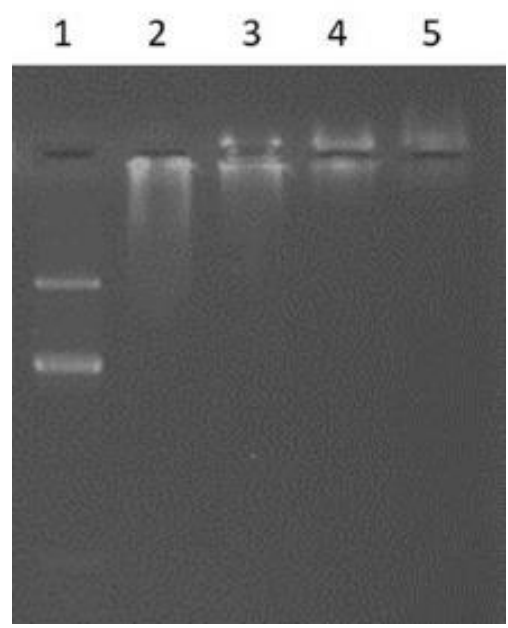

Figure 2. Gel retardation assay in which nanoparticles were run through $2 \%$ agarose gel. The mobility of siRNA was visualized by ethidium bromide staining. (1: Naked siRNA, 2,3,4,5: cSLN:siRNA complexes for the ratio $1: 1,2: 1,3: 1,4: 1(v / v)$, respectively).

\subsection{Serum Stability}

Formation of the compact complex is an important issue for gene delivery systems as well as the protection ability of the nucleic acids from serum nucleases [19]. The protection ability of cSLNs was evaluated by serum stability assay. Serum stability assay revealed that cSLN:siRNA complexes prepared at 3:1 (v/v) ratio was able to protect siRNA from enzymatic digestion due to nucleases completely for $6 \mathrm{~h}$ and substantially up to $24 \mathrm{~h}$, whereas most of the naked siRNA was degraded in 1 hours (Figure 3) This evidence confirmed that obtained SLNs have efficient ability to protect siRNA-EGFR from degradation in physiological conditions [20].

\subsection{Cytotoxicity}

All excipients used in this study were selected due to their low cytotoxic properties [21,22]. The results obtained from XTT cytotoxicity assay on U87 cells support this fact, as well. No significant cytotoxicity was observed on U87 cells in the concentration range of $25,50,75,100 \mu \mathrm{l} / \mathrm{mL}(\mathrm{p}<0,05)$. All formulations showed a concentration dependent cytotoxicity in the cell viability (Figure 4). According to cytotoxicity results, cell viability drops lower than $70 \%$ after cultured with $10 \mu \mathrm{L}$ cSLN formulation while it sustains around $80 \%$ for cSLN:siRNA (3:1, v/v ) complexes. This may be due to higher zeta potential of cSLN alone. It is well known that positively charged nanoparticles act more cytotoxic than negative variants of similar size because of their disruption effect on the cell membrane [23, 24].

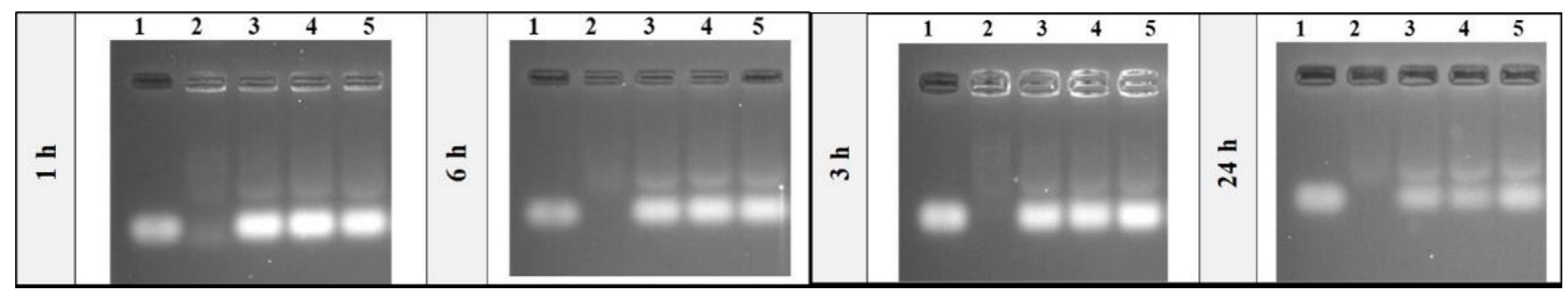

Figure 3. Agarose gel electrophoresis image of naked siRNA and siRNA released from cSLN:siRNA complexes for different time points. (1:Control; 2:Naked siRNA incubated with serum, 3, 4, 5: siRNA released 
from cSLN:siRNA complexes following incubation with serum for the cSLN:siRNA ratio 3:1, 4:1, 5:1 (v:v), respectively).

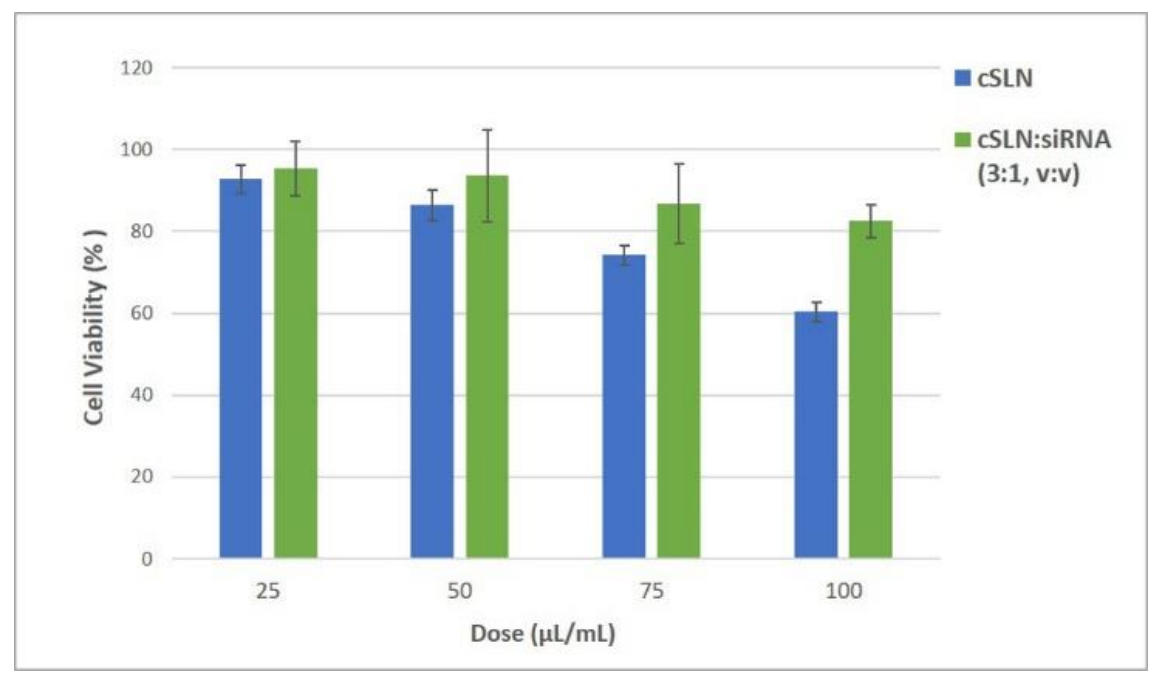

Figure 4. Cell viability of U87 cells exposed to cSLN and cSLN:siRNA formulations (Data are shown as mean \pm standard error of the mean, $n=3$ ).

\subsection{Quantitative assessment of EGFR mRNA expression levels by qRT- PCR}

The EGFR is one of the oncogenes which plays an important role in many types of cancer, including glioblastoma. EGFR overexpression or overactivation was observed more than $50 \%$ of the patients [2,12,25]. Therefore, specific anti-EGFR treatment options have been developed in the last decades [26-28]. For this aim, we tried to knockdown the level of EGFR expression by cSLN:siRNA-EGFR (3:1, v/v) in human glioblastoma cell line.

U87 cells were cultured in the presence cSLN, free siRNA-EGFR, and cSLN:siRNA-EGFR complexes for increasing siRNA amount. The EGFR silencing efficiency was determined using quantitative RT-PCR. As it is shown in Figure 5, when cSLN alone applied on U87 cells, no significant effect observed compared to nonthreated cells. On the other hand, cSLN:siRNA-EGFR (3:1,v/v) generated significant EGFR inhibition at $50 \mathrm{nM}$ and $100 \mathrm{nM}$ siRNA doses compared to free siRNA-EGFR at $50 \mathrm{nM}$ dose $(\mathrm{p}<0.05)$.

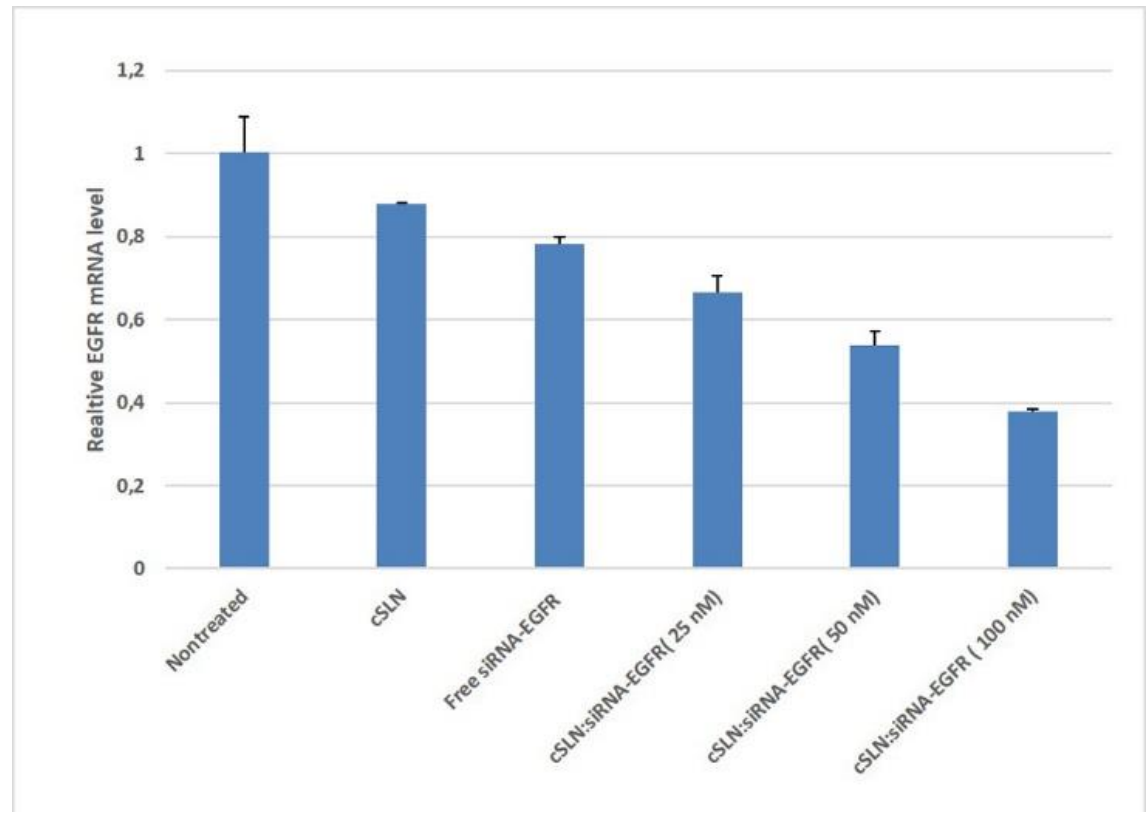

Figure 5. Determination of EGFR expression on U87MG cells after treatment by the EGFR siRNA for 48 hours (Data are shown as mean \pm standard error of the mean, $n=3$ ). 


\section{CONCLUSION}

The present study focused on the development of a novel positive-charged solid lipid nanoparticle for the delivery of siRNA-EGFR to the glioblastoma cells. Obtained nanoparticles have appropriate particle size, zeta potential, protection ability against serum nucleases, and low toxicity. The EGFR gene suppression was decreased significantly by obtained nanoparticle siRNA complex. Consequently, developed positive-charged solid lipid nanoparticles are considered promising vehicles for non-viral gene delivery system for the treatment of glioblastoma.

\section{MATERIALS AND METHODS}

\subsection{Materials}

siRNA targeting the EGFR gene, was purchased from Invitrogen (USA). The siRNA sequence was as follows: 5' - CGG AAU AGG UAU UGG UGA AUU UAA A-3' (sense). Cetyl Palmitate and Cremophor RH 40 were kindly donated by BASF (Germany). Peceol was gifted from Gattefosse (France). Dimethyldioctadecylammonium bromide (DDAB) was provided from Avanti Lipids (USA). Ethanol was obtained from Merck-Co. (Germany). Human primary glioblastoma cell line (U87) were obtained from American Type Culture Collection (USA). XTT cell proliferation assay kit was provided from Biological Industries (Israel). All other chemicals were of analytical grade and used as received. Ultrapure water (UPH2O) was used in all stages needed as a water.

\subsection{Methods}

\subsubsection{SLN synthesis}

For the delivery of concerned genetic materials, solid lipid nanoparticles (SLNs) were developed by modified microemulsion dilution technique by using cetyl palmitate as matrix lipid, Cremephor RH40 and Peceol $(2: 1, \mathrm{v} / \mathrm{v})$ as surfactants, ethanol as co-surfactant, and distilled water as dispersant. Then, 1 volume of hot oil-in-water microemulsion was dispersed into 9 volume of cold UPH2O $\left(2-3^{\circ} \mathrm{C}\right)$ to produce solid lipid nanoparticles (SLN). To obtain cationic SLNs (cSLN), DDAB was incorporated into the formulation as positive charge carrier at the oil-in-water microemulsion preparation step.

\subsubsection{Preparation of cSLN:siRNA complexes}

cSLN : siRNA complexes were formed by electrostatic interactions between cationic charged nanoparticles and anionic charged siRNA. The binding ability of siRNA with cSLN determined by $2 \%(\mathrm{w} / \mathrm{v})$ agarose gel electrophoresis. For complex formation, a stock solution of siRNA-EGFR $(20 \mu \mathrm{M})$ was prepared in nuclease-free ultrapure water. cSLN:siRNA-EGFR complexes were prepared by incubating siRNA-EGFR (20 $\mu \mathrm{M})$ with $\mathrm{CSLN}$ for 30 minutes at $25^{\circ} \mathrm{C}$ for increasing CSLN:siRNA ratios $(1: 1,2: 1,3: 1,4: 1,5: 1(\mathrm{v} / \mathrm{v}))$ to determine the optimal cSLN:siRNA ratio. Glycerol ( $2 \%)$ was added to each sample and electrophoresis was carried out at a constant voltage of $80 \mathrm{~V}$ for $45 \mathrm{~min}$. After electrophoresis, the gel was stained in $500 \mathrm{ng} / \mathrm{ml}$ ethidium bromide solution for $20 \mathrm{~min}$. In order to remove the excess ethidium bromide and to reduce the background fluorescence, the gel was washed with distilled water for the following $10 \mathrm{~min}$. The siRNA bands were then visualized under a UV transilluminator. Naked siRNA was used as a control.

\subsubsection{Size and Zeta Potential Measurements}

The particle size and zeta potential values of SLN, cSLN and cSLN:siRNA-EGFR (3:1, v/v) complexes were measured by Dynamic Light Scattering (DLS, Zeta sizer Nano ZS, Malvern Instruments Ltd., UK) using non-invasive back scattering mode with the detector positioned at $173^{\circ}$ from the incident beam. Samples were filled in disposable polystyrene microcuvettes and three measurements were performed for each sample.

Electrophoretic mobility of the obtained nanoparticles was measured in standard zeta cuvettes (Malvern Instruments Ltd., UK) and the zeta potential was calculated by the software using Smoluchowski equation.

\subsubsection{In vitro serum stability of complexed siRNA}

To evaluate the protection ability of cSLN:siRNA complexes against serum nucleases, in vitro serum stability assay was performed. For this purpose, serum was isolated from fresh blood obtained from a healthy 
volunteer. Following the precipitation of the coagulation factors, fibrinogen, and blood cells, the whole blood was centrifuged for $10 \mathrm{~min}$ at $4000 \mathrm{rpm}$ and the supernatant, consisting of serum was carefully collected. Selected cSLN:siRNA complexes (3:1, 4:1, 5:1, v/v) were prepared, then, serum (10\%) was added onto the complexes and incubated at $37^{\circ} \mathrm{C}$. The integrity of siRNA-EGFR was observed at each predetermined time intervals $(1,3,6$, and $24 \mathrm{~h})$. At the end of the incubation period, SDS at the final concentration of $1 \%$ was added to stop the enzymatic reactions and release the siRNA. The integrity of siRNA was visualized by agarose gel electrophoresis [14].

\subsubsection{Cytotoxicity}

The cytotoxicity assay was performed on human glioblastoma cell line (U87). Dulbecco's Modified Eagle's Medium (DMEM) supplemented with $10 \%$ fetal bovine serum (FBS) and $2 \mathrm{mM}$ L- glutamine was used as culture medium. Penicillin-streptomycin (100 UI/ml penicillin, $100 \mu \mathrm{g} / \mathrm{ml}$ streptomycin) was added to prevent bacterial contamination.

The U87 cells were seeded into 96 well plate at the concentration 1x104 cells/well and incubated for 24 $\mathrm{h}$ at $37^{\circ} \mathrm{C}$ in a humidified $5 \% \mathrm{CO} 2$ atmosphere. Then, the medium was removed and the cells were washed with PBS $(\mathrm{pH}=7,4) .100 \mu$ l DMEM supplemented with 10\% FBS containing different concentrations of cSLN and cSLN:siRNA $(3: 1, \mathrm{v} / \mathrm{v})$ complexes $(25,50,75,100 \mu \mathrm{l} / \mathrm{mL})$ were added into the wells.

The viability of cells was determined by colorimetric XTT cell proliferation assay kit (Biological Industries, Israel). Briefly, after incubation for $24 \mathrm{~h}$, the medium was removed and the cells washed twice with PBS ( $\mathrm{pH}=7.4)$. Then, $100 \mu \mathrm{l}$ DMEM and $50 \mu \mathrm{l}$ activated XTT reagent was added to each well and the cells were incubated for $2 \mathrm{~h}$ as recommended by the manufacturer. The absorbance of the orange-colored metabolite of XTT reagent was measured at wavelengths of $475 \mathrm{~nm}$ and $660 \mathrm{~nm}$ by Varioskan Multiplate Reader (Thermo Scientific, USA). Specific absorbance (SA) values were calculated using the following equation [29].

$$
\mathrm{SA}=\mathrm{A}_{475}\left(\text { test) }-\mathrm{A}_{475}\left(\text { blank)- } \mathrm{A}_{660}(\text { test })\right.\right.
$$

Cell viability was calculated based on the specific absorbance of the cells compared to the absorbance of the control group consisting of untreated U87 cells. Experiments were carried out at least in triplicate.

\subsubsection{Quantitative assessment of EGFR $m R N A$ expression levels by $q R T$ - PCR}

Human U87 glioma cells were cultivated on the 12 well plate at the density of $5 \times 10^{4}$ cells/well and precultured overnight. Before transfection, the medium was changed to a fresh medium containing $10 \% \mathrm{FBS}$. 1,2 and $4 \mu \mathrm{L} / \mathrm{mL}$ cSLN:siRNA-EGFR (3:1, v/v) were added into the wells as the final siRNA concentrations of 25, 50, $100 \mathrm{nM}$, respectively. The naked siRNA $(50 \mathrm{nM})$ and the cSLN $(2 \mu \mathrm{L} / \mathrm{mL})$ were also added into the wells, separately. Then, the cells were incubated for $24 \mathrm{~h}$. Afterwards, the cells were washed with phosphate buffered saline (PBS) and put back into serum condition media for a further $24 \mathrm{~h}$.

Treated cells were harvested after $48 \mathrm{~h}$ post-transfection, and RNA was isolated (Miniprep, Qiagen). Subsequently, a cDNA template was created via a reverse polymerase reaction and a real-time quantitative polymerase chain reaction (RT-qPCR) was performed on these samples. Primer pairs were used to detect EGFR and GAPDH as a housekeeping gene. The results were analyzed with the $\Delta \Delta \mathrm{CT}$ method with untreated cells as controls.

\subsubsection{Data analysis}

Statistical analysis was performed using GraphPad Prism 6.0 (GraphPad Software, Inc., USA). Results are expressed as means \pm SEM. Quantitative assessment of EGFR mRNA levels were analyzed by using Student's t-test, and the differences were judged to be significant at $\mathrm{p}<0.05$.

\footnotetext{
Acknowledgements: This work has been supported by Scientific Human Resources Development Program (ÖYP) of the Turkish Higher Education Council (YÖK). We appreciate the project 108 S083 (TUBITAK-SBAG) which the Malvern Zetasizer Instrument was purchased. Dr. Bilge Debeleç Bütüner from the Department of Pharmaceutical Biotechnology, Faculty of Pharmacy, Ege University is greatly appreciated for kindly providing the U87 cells.

Authorship contributions: Concept - G.E.A., A.G.K.; Design - G.E.A., A.G.K.; Supervision - A.G.K.; Resource - G.E.A., A.G.K.; Materials - G.E.A., H.A., A.G.K.; Data Collection and/or Processing - G.E.A., A.G.K.; Analysis and/or Interpretation - G.E.A., H.A., A.G.K.; Literature Search - G.E.A., H.A., A.G.K.; Writing - G.E.A., H.A., A.G.K.; Critical Reviews - G.E.A., H.A., A.G.K.
} 
Conflict of interest statement: The authors declared that there are no conflicts of interest. The authors alone responsible for the content and writing of the paper.

\section{REFERENCES}

[1] Alifieris C, Trafalis DT. Glioblastoma multiforme: Pathogenesis and treatment. Pharmacol Ther. 2015; 152: 63-82.

[2] Danhier F, Messaoudi K, Lemaire L, Benoit J-P, Lagarce F. Combined anti-Galectin-1 and anti-EGFR siRNA-loaded chitosan-lipid nanocapsules decrease temozolomide resistance in glioblastoma: In vivo evaluation. Int J Pharm. 2015; 481(1-2): 154-161.

[3] Brower JV, Clark PA, Lyon W, Kuo JS. MicroRNAs in cancer: Glioblastoma and glioblastoma cancer stem cells. Neurochem Int. 2014; 77: 68-77.

[4] Wang G, Wang JJ, Tang HM, To SST. Targeting strategies on miRNA-21 and PDCD4 for glioblastoma. Arch Biochem Biophys. 2015; 580: 64-74.

[5] Kuşçu L, Sezer AD. Gen Tedavisi İçin Tasarlanan ve Patent Başvurusu Yapılan Farmasötiklerin İncelenmesi ve Değerlendirilmesi. Marmara Pharm J. 2016; 20(2): 52-63.

[6] Wissing SA, Kayser O, Müller RH. Solid lipid nanoparticles for parenteral drug delivery. Adv Drug Deliv Rev. 2004; 56(9): 1257-1272.

[7] Yang S, Zheng Y, Chen J, Zhang Q, Zhao D, Han D, Chen X. Comprehensive study of cationic liposomes composed of DC-Chol and cholesterol with different mole ratios for gene transfection. Coll Surf B. 2013; 101: 6-13.

[8] Uprit S, Kumar Sahu R, Roy A, Pare A. Preparation and characterization of minoxidil loaded nanostructured lipid carrier gel for effective treatment of alopecia. Saudi Pharm J. 2013; 21(4): 379-385.

[9] Büyükköroğlu G, Şenel B, Başaran E, Yenilmez E, Yazan Y. Preparation and in vitro evaluation of vaginal formulations including siRNA and paclitaxel-loaded SLNs for cervical cancer. Eur J Pharm Biopharm. 2016; 109: 174-183. .

[10] Jin SE, Kim CK. Charge-mediated topical delivery of plasmid DNA with cationic lipid nanoparticles to the skin. Coll Surf B. 2014; 116: 582-590.

[11] Kotmakçı M, Akbaba H, Erel G, Ertan G, Kantarcı G. Improved Method for Solid Lipid Nanoparticle Preparation Based on Hot Microemulsions: Preparation, Characterization, Cytotoxicity, and Hemocompatibility Evaluation. AAPS PharmSciTech. 2017; 18(4): 1355-1365.

[12] Resnier P, David S, Lautram N, Delcroix GJR, Clavreul A, Benoit JP. EGFR siRNA lipid nanocapsules efficiently transfect glioma cells in vitro. Int J Pharm. 2013; 454(2): 748-755.

[13] Van Woensel M, Wauthoz N, Rosière R, Mathieu V, Kiss R, Lefranc F. Development of siRNA-loaded chitosan nanoparticles targeting Galectin-1 for the treatment of glioblastoma multiforme via intranasal administration. J Control Release. 2016; 227: 71-81.

[14] Kotmakçı M, Çetintaş VB, Kantarcı AG. Preparation and characterization of lipid nanoparticle/pDNA complexes for STAT3 downregulation and overcoming chemotherapy resistance in lung cancer cells. Int J Pharm. 2017; 525(1): 101111.

[15] Kim HR, Kim IK, Bae KH, Lee SH, Lee Y, Park TG. Cationic solid lipid nanoparticles reconstituted from low density lipoprotein components for delivery of siRNA. Mol Pharm. 2008; 5(4): 622-631.

[16] Gooding M, Malhotra M, McCarthy DJ, Godinho BMDC, Cryan JF, Darcy R. Synthesis and characterization of rabies virus glycoprotein-tagged amphiphilic cyclodextrins for siRNA delivery in human glioblastoma cells: in-vitro analysis. Eur J Pharm Sci. 2015; 71: 80-92.

[17] Aral C, Akbuga J. Preparation and in vitro transfection efficiency of chitosan microspheres containing plasmid DNA:poly(L-lysine) complexes. J Pharm Pharm Sci. 2003; 6(3): 321-326.

[18] Şalva E, Akbuğa J. The Effects to GM-CSF Expression and Fibroblast Proliferation of pGMCSF Containing Chitosan/PVP Hydrogels. Marmara Pharm J. 2016; 21(2): 228-234.

[19] Xu C, Wang J. Delivery systems for siRNA drug development in cancer therapy. Asian J Pharm Sci. 2015; 10(1): 1-12.

[20] Liu Y, An S, Li J, Kuang Y, He X, Guo Y, Ma H, Zhang Y, Ji B, Jiang C. Brain-targeted co-delivery of therapeutic gene and peptide by multifunctional nanoparticles in Alzheimer's disease mice. Biomaterials. 2015; 80:33-45. 
[21] Müller RH, Mäder K, Gohla S. Solid lipid nanoparticles (SLN) for controlled drug delivery - A review of the state of the art. Eur J Pharm Biopharm. 2000; 50(1): 161-177.

[22] Sachs-Barrable K, Thamboo A, Lee SD, Wasan KM. Lipid excipients peceol and gelucire 44/14 decrease P-glycoprotein mediated efflux of Rhodamine 123 partially due to expression within Caco-2 cells. J Pharm Pharm Sci. 2007; 10(3): 319-331.

[23] Fröhlich E. The role of surface charge in cellular uptake and cytotoxicity of medical nanoparticles. Int J Nanomedicine. 2012; 7: 5577-5591.

[24] Albuquerque J, Costa Moura C, Sarmento B, Reis S. Solid lipid nanoparticles: A potential multifunctional approach towards rheumatoid arthritis theranostics. Molecules. 2015; 20: 11103-11118.

[25] Messaoudi K, Saulnier P, Boesen K, Benoit JP, Lagarce F. Anti-epidermal growth factor receptor siRNA carried by chitosan-transacylated lipid nanocapsules increases sensitivity of glioblastoma cells to temozolomide. Int J Nanomedicine. 2014; 9: 1479-1490.

[26] Yang HW, Lu YJ, Lin KJ, Hsu SC, Huang CY, She SH. EGFR conjugated PEGylated nanographene oxide for targeted chemotherapy and photothermal therapy. Biomaterials 2013; 34(29): 7204-7214.

[27] Chirio D, Gallarate M, Peira E, Battaglia L, Muntoni E, Riganti C. Positive-charged solid lipid nanoparticles as paclitaxel drug delivery system in glioblastoma treatment. Eur J Pharm Biopharm. 2014; 88(3): 746-758.

[28] Taylor TE, Furnari FB, Cavenee WK. Targeting EGFR for Treatment of Glioblastoma: Molecular Basis to Overcome Resistance. Curr Cancer Drug Targets. 2012; 12(3): 197-209.

[29] Erel Akbaba G, Kotmakçı M, Akbaba H, Sözer Karadağlı S, Kantarcı AG. Nanoencapsulated chitosan nanoparticles in emulsion-based oral delivery system: In vitro and in vivo evaluation of insulin loaded formulation. J Drug Deliv Sci Technol. 2016; 36:161-167.

This is an open access article which is publicly available on our journal's website under Institutional Repository at http://dspace.marmara.edu.tr. 